\title{
Choice of prosthetic heart valve in a developing country
}

\author{
Shiv Kumar Choudhary, Sachin Talwar, Balram Airan
}

Cardiothoracic Centre, All India Institute of Medical Sciences, New Delhi, India

\section{Correspondence to} Dr Shiv Kumar Choudhary, Department of Cardiothoracic and Vascular Surgery, All India Institute of Medical Sciences, New Delhi 110029, India; shivchoudhary@gmail.com

Received 25 January 2016 Revised 29 March 2016 Accepted 30 March 2016

\section{SLinked}

- http://dx.doi.org/10.1136/ heartasia-2015-010660

- http://dx.doi.org/10.1136/ heartasia-2016-010734

\section{CrossMark}

To cite: Choudhary SK,

Talwar S, Airan B. Heart

Asia 2016:8:65-72.

doi:10.1136/heartasia-2015-

010650

\section{ABSTRACT}

Mechanical prostheses and stented xenografts (bioprosthesis) are most commonly used substitutes for aortic and mitral valve replacement. The mechanical valves have the advantage of durability but are accompanied with the risk of thromboembolism, problems of long-term anticoagulation, and associated risk of bleeding. In contrast, bioprosthetic valves do not require long-term anticoagulation, but carry the risk of structural valve degeneration and re-operation. A mechanical valve is favoured in young patients $(<40$ years) if reliable anticoagulation is ensured. In elderly patients ( $>60$ years), a bioprosthesis is a suitable substitute. In middle-aged patients (40-60 years), risk of re-operation in a bioprosthesis is equal to that of bleeding in a mechanical valve. Traditionally, a bioprosthesis is opted in patients with limited life expectancy. Calculation of life expectancy, based solely upon chronological age, is erroneous. In developing countries, the calculated life expectancy is much lower than that of Western population, hence age related Western cut-offs are not valid in developing countries. Besides age, cardiac condition of the patient, systemic illnesses, socio-economic status, gender and geographical location also decide the life expectancy of the patients. Selection of the prosthetic valve substitute should be based on: aspiration of the patient, life expectancy, socio-economic and educational background, occupation of the patient, availability, cost, monitoring of anti-coagulation, monitoring of valve function and other valve related complications, and possibility of reoperation.

\section{INTRODUCTION}

The surgical replacement of diseased heart valves is based on the premise that the prosthesis chosen to replace a diseased heart valve will improve or prevent further deterioration of heart function, relieve symptoms, improve functional status, and prolong overall survival. Thus, it is a trade-off between the natural course of the disease and the risks of surgery and the recognised complications of prosthetic heart valves. Among the available valve substitutes, none is closest to being 'ideal'. ${ }^{1}$ Each valve substitute has some inherent advantages and disadvantages, and is not suitable for all patient subgroups. Mechanical prostheses and stented xenografts (bioprosthesis) are the most commonly used substitutes for aortic and mitral valve replacement (MVR). In addition, for aortic valve replacement (AVR), autograft/homograft or stentless xenografts are other options. However, because of their limited availability, technical complexity, and difficult reoperations, autograft/homograft and stentless xenografts are used for specific indications in a limited subset of patients. ${ }^{2}$ Thus, in most circumstances, the choice remains between a mechanical valve and a bioprosthesis.

Easy availability and durability are the advantages of the mechanical valves. However, mechanical valves require lifelong anticoagulation. Thus, mechanical valves impose the mortality and morbidity related to anticoagulation. On the other hand, with a bioprosthesis, anticoagulation is usually not required after a period of 3-6 months. However, depending upon the age at implantation and the type of bioprosthesis, it starts degenerating after 5-10 years. Hence, if the patient survives long enough, there is a mandatory risk of reoperation.

Various factors that need to be considered at the time of selection of a prosthesis are listed in table 1 . The most important factors that should be considered are the patient's age, life expectancy, preference, indication/contraindication/acceptance for warfarin therapy, the patient's tolerance to the need for repeat valve replacement, and comorbidities.

\section{POINTS OF CONSENSUS}

Choosing the most suitable prosthetic heart valve should be a shared decision-making process that accounts for the patient"s values and preferences, with full disclosure of the indications for and the risks of anticoagulant therapy and the potential need for and risk of reoperation. ${ }^{3}$ A mechanical valve is favoured in: (1) an informed patient who wants a mechanical valve and has no contraindication to long-term anticoagulation; (2) the patient who is already on anticoagulation (mechanical prosthesis in another position or at high risk for thromboembolism); (3) the patient who is at risk of accelerated bioprosthesis structural deterioration (young age, hyperparathyroidism, renal insufficiency); and (4) the patient with a long life expectancy. In younger patients, bioprostheses degenerate much faster, ${ }^{4} 5$ and if a bioprosthesis is used in younger patients ( $<40$ years), they will require multiple reoperations. Each subsequent reoperation entails operative risk much higher than the previous one. Thus, the risk of reoperations becomes prohibitive. It is also accompanied with the burden of cost of multiple reoperations. Therefore, in this age group a mechanical valve is the well-accepted option in most patients. On the other hand, a bioprosthesis may be preferred in: (1) an informed patient who wants a bioprosthesis; (2) patients where anticoagulation is not desired (lifestyle), not feasible (compliance problems, availability or monitoring issues) or is contraindicated; (3) a female patient of childbearing age with a history of 
Table 1 Factors to be considered in selection of prosthesis

\begin{tabular}{ll}
\hline $\begin{array}{l}\text { Serial } \\
\text { number }\end{array}$ & Factors affecting the choice of prosthesis \\
\hline 1 & Patient's wishes and expectations \\
2 & Age/gender of the patient \\
3 & $\begin{array}{l}\text { Life expectancy (estimated according to age, gender, } \\
\text { comorbidities, and country-specific life expectancy) }\end{array}$ \\
4 & Socioeconomic status/education \\
5 & Comorbid conditions-cardiac and non-cardiac \\
6 & Need for anticoagulation. \\
7 & Contraindication of anticoagulation \\
8 & Probability of adherence and compliance with warfarin therapy \\
9 & Quality and availability of medical services \\
10 & Lifestyle, profession \\
11 & Pregnancy contemplated \\
12 & Size of left ventricular cavity (in mitral valve replacement) \\
13 & Cost and availability of prosthesis \\
\hline
\end{tabular}

repeated abortions who intends to become pregnant, and (4) a patient with limited life expectancy. If the life expectancy of the patient is less than that of the bioprosthesis, then a bioprosthesis is the more likely choice. Life expectancy may be limited because of associated comorbid conditions or advanced age. In various guidelines, ${ }^{3}{ }^{6}$ based on the characteristics of Western populations, a cut-off age of 60-65 years has been suggested to define advanced age. However, this may not be applicable in developing countries and more deliberations on this matter are required.

\section{POINTS OF DEBATE}

The average lifespan of a bioprosthesis, implanted at the age of $60-65$, is about 15 years. As the average life expectancy in Western populations ranges from $75-80$ years, a bioprosthesis is considered as a suitable substitute beyond 60 years of age. ${ }^{3} 6$ These age cut-offs are set at the point where the risk of future reoperation after bioprosthesis implantation is eliminated. In middle-aged patients $<60$ years of age, a mechanical prosthesis is considered reasonable. However, this approach is not supported by robust evidence and raises three important questions:

I. Is there any distinct advantage of using a mechanical valve in middle-aged patients (40-60 years)?

II. Is life expectancy dependent only upon chronological age?

III. Is the cut-off age of 60-65 years in the current American and European guidelines ${ }^{3}{ }^{6}$ applicable to developing countries?

\section{MECHANICAL VALVE VERSUS STENTED BIOPROSTHESIS}

The advantageous durability of mechanical valves is offset by the risk of thromboembolism, the need for long-term anticoagulation, and associated risk of bleeding. In contrast, bioprosthetic valves do not require long-term anticoagulation, but carry the risk of structural failure and reoperation. ${ }^{7-9}$ To answer the question regarding the superiority of one type of valve over another, there is a need for robust long-term outcome data using the current generation of bioprosthesis/mechanical valves in both the aortic and the mitral position in large numbers of patients of all age groups. However, no such data are available. In the absence of large, multicentred, randomised clinical trials, inferences are drawn from the existing literature, an approach which has several shortcomings. Minimal data are available about the use of newer bioprostheses. Most of the published reports related to bioprostheses pertain to the elderly ( $>60$ years) population. Very few reports are available pertaining to the use of bioprostheses in middle aged (40-60 years) subjects. Similarly, most of the published reports address the aortic valve. There is a paucity of long-term results on MVR with bioprostheses or mechanical valves. Finally, almost negligible information is available from developing countries. All the major studies are from the developed world. In the absence of perfect data, we will build our case using available evidence.

\section{Bleeding and anticoagulation}

Need for life-long oral anticoagulation and associated bleeding complications are the major drawbacks of mechanical valves. Stented bioprostheses also need oral anticoagulants in the early phase. Some patients with bioprostheses may continue to receive oral anticoagulants for an extended period for indications not related to bioprostheses. In its present form, oral anticoagulation therapy is accompanied by several problems.

Anticoagulation therapy, not infrequently, results in internal or external bleeding episodes that can cause death, stroke, reoperation and hospitalisation. With an international normalised ratio (INR) of 2.0-3.0, the annual risk of a major bleeding episode is approximately $1-2 \%$ per patient-year. ${ }^{10}$ The two earliest randomised controlled trials (the Veterans Affairs study and the Edinburgh study) showed statistically significant increases in bleeding with mechanical valves. ${ }^{11}{ }^{12}$ Risk of bleeding is higher in patients with mechanical valves requiring higher anticoagulation. ${ }^{12} 13$ In micro-simulation, the simulated lifetime risk of bleeding was $12 \%$ with a bioprosthesis valve versus $41 \%$ with a mechanical valve for a 60 -year-old man. ${ }^{14}$ The risk of bleeding is much higher in elderly patients. In patients with mechanical valves and the same level of anticoagulation therapy, patients $>60$ years of age had up to seven times higher bleeding rates than patients $<60$ years of age. ${ }^{15}$ Among patients 75 years of age, the bleeding rate was greatly increased in those with a mechanical valve compared with those who received a bioprosthesis (OR 18.9, 95\% CI 2.2 to $163.0 ; \mathrm{p}=0.007) .{ }^{16}$ Major bleeding episodes are associated with very high (13-22\%) mortality. ${ }^{14} 17$

It is difficult to maintain an adequate INR in the therapeutic range. In developed countries, with better and more frequent anticoagulation monitoring, the INR could be maintained in the therapeutic range in $40-60 \%$ of patients. ${ }^{18}{ }^{19}$ In developing countries, however, where patients from remote areas travel to cities once or twice a year for anticoagulation monitoring, this figure is as low as $25 \% .^{20}$ Patients who are not within the therapeutic range are exposed to bleeding risk if the INR is higher, or thromboembolism if the INR is lower. Patients with bioprostheses either do not need anticoagulation or require a lower degree of anticoagulation without the risk of valve thrombosis. Hence, patients with bioprostheses are not exposed to these risks.

There are other major problems associated with lifetime anticoagulation therapy including frequent blood draws, drug-drug interactions, dietary and activity restrictions, and the cost of medicine. In developing countries, patients have to travel long distances for anticoagulation monitoring, resulting in vocational losses. Oral anticoagulants may have to be discontinued, for at least a period of time, because of major bleeding, or because of the need for non-cardiac surgical/non-surgical procedures. This exposes patients to the risks of thromboembolism and of mechanical prosthetic heart valve thrombosis, and resultant heart failure, embolism, and mortality. ${ }^{21} 22$

A special mention is required about those patients who need anticoagulation for atrial fibrillation (AF) or any other indication 
Table 2 Risk factors for bioprosthesis structural valve degeneration ${ }^{13} 23-26$

\begin{tabular}{ll}
\hline Serial number & Risk factor \\
\hline 1 & Younger age at implantation \\
2 & Mitral position \\
3 & Older generation of bioprosthesis \\
4 & Renal insufficiency \\
5 & Hyperparathyroidism \\
6 & Hypertension \\
7 & Left ventricular hypertrophy \\
8 & Left ventricular dysfunction \\
\hline
\end{tabular}

not related to valve prosthesis. Some investigators would support the use of a mechanical valve in such cases as the patient is already on oral anticoagulants for AF. Several factors need to be considered before adopting such an approach. Firstly, a patient with AF requires a lower INR compared with a patient with a mechanical valve, especially in the mitral position. Secondly, a patient with a mechanical valve requires a much higher INR in the presence of $\mathrm{AF}$, and thus bleeding risk increases exponentially. Thirdly, recently introduced direct thrombin inhibitors and factor Xa inhibitor can be used to treat $\mathrm{AF}$, but are not recommended for mechanical valves. Lastly, in some cases, it is possible to treat AF with surgical or catheter intervention. Thus, it may not be prudent to commit a patient to lifetime anticoagulation by choosing a mechanical valve for AF only.

\section{Structural valve deterioration and reoperations}

All available bioprostheses develop structural valve deterioration (SVD) and ultimately fail. Major risk factors for SVD are listed in the table $2 .^{13}{ }^{23-26}$ SVD is strongly influenced by the age of the patient at the time of implantation (table 3$).{ }^{27}$

Patients $>65$ years of age have a much lower rate of SVD than those $<65$ years. ${ }^{12}$ The cumulative 15 - to 20 -year risk of SVD at implantation of 60 and 55 years of age averages $25 \%$ and $34 \%$, respectively. Burdon and colleagues ${ }^{4}$ found that after 15 years of follow-up, only a third of patients who had received a bioprosthesis for AVR between the ages of 16-39 years remained free of SVD, compared with more than $90 \%$ of those over 70 at the time of implantation. The Edinburgh trial ${ }^{11}$ found an increased risk of porcine valve failure in younger patients with a relative risk of approximately 1.5 for every 10 years of age. SVD after MVR with first generation porcine bioprostheses begins at about 5 years, and at about 8 years after AVR. ${ }^{11} 12$ After 10 years of AVR, SVD begins to have a deleterious effect on survival. ${ }^{12}$

Advances in tissue fixation and anti-calcification treatment have resulted in current-generation bioprostheses that have

Table 3 Durability of bioprosthetic valves in the aortic position as a function of the age of the patient ${ }^{27}$

\begin{tabular}{llll}
\hline Age (years) & $\mathbf{5}$ years $(\%)$ & $\mathbf{1 0}$ years $(\%)$ & $\mathbf{1 5}$ years $(\%)$ \\
\hline$<35$ & 79 & 51 & \\
$36-50$ & 99 & 68 & 48 \\
$51-64$ & 98 & 72 & 42 \\
$65-69$ & 98 & 74 & 64 \\
$>70$ & 100 & 90 & 90 \\
\hline
\end{tabular}

superior durability compared with the first generation bioprostheses. $^{2628}$ The second generation Hancock II aortic valve had $81 \pm 5 \%$ freedom from SVD after 15 years in patients with a mean age of 65 years at the time of implantation, ${ }^{28}$ which was better than $57 \pm 4 \%$ freedom from SVD at 15 years in patients with a mean age of 69 years using the first-generation Hancock bioprosthesis. $^{29}$ Similarly, the Carpentier-Edwards pericardial aortic valve had $94 \%$ freedom from SVD at 10 years and $77 \%$ at 15 years in patients with a mean age of 65 years. ${ }^{30}$ After MVR in patients $<60$ years of age, SVD at 10 years was 16 $\pm 3.7 \%$ with the C-E pericardial valve versus $35.3 \pm 3.3 \%$ with the C-E porcine valve $(p<0.05)$; and SVD at 10 years for patients $61-70$ years of age was $4.8 \pm 2.1 \%$ with the C-E pericardial valve versus $24.8 \pm 3.7 \%$ with the C-E porcine valve $(\mathrm{p}<0.05) .{ }^{31}$ The third-generation bioprostheses are even more durable, with $92 \pm 8 \%$ freedom from SVD 12 years after implantation of an aortic bioprosthesis in patients with a mean age of 54 years at the time of surgery. ${ }^{32}$ Current bioprostheses are significantly more durable in the aortic position than in the mitral position $(14.3 \pm 6.8 \%$ more freedom from 15 -year reoperation; $\mathrm{p}<0.018) .^{26}$

Minimal data are available on the use of second generation and newer bioprostheses in middle aged persons. From the data available, it can be inferred that if a second generation bioprosthesis is used in a patient 40 years of age, on average it is going to fail at 10 years in the mitral position, and at 12 years in the aortic position. Third generation bioprostheses are expected to last a little longer, more so in older patients (50-60 years).

If patients survive long enough, eventually all those with bioprostheses will need to undergo reoperation. If patients are operated on between 40 and 60 years of age, the linearised reoperation rate ranges from $3.5 \%$ to $4.3 \%$ per patient-year. ${ }^{33}$ For the first $8-10$ years reoperation is rarely required, but almost all these patients will require reoperation after 12-20 years of follow-up. Chan et $a l^{34}$ reported that the median interval to reoperation in patients undergoing AVR with current generation stented aortic bioprostheses was 7.7 years in patients aged $<40$ years, and 12.9 years in patients between 40 and 60 years of age. The actuarial freedom from structural valve degeneration and reoperation, in patients $<40$ years of age who underwent mostly MVR with the Hancock II porcine bioprosthesis, was $70.6 \pm 5.2 \%$ and $66 \pm 5.7 \%$, respectively. ${ }^{20}$ No valve was explanted for structural degeneration within 5 years.

The mortality rate for the first reoperation at the age of 5065 years ranges from $5 \%$ to $7 \% .^{7} 35-37$ The mortality for a second reoperation in elderly patients is about $12 \%$. However, mortality from reoperation secondary to bioprosthetic aortic structural failure can be lowered by reoperation in patients with low, rather than high, New York Heart Association (NYHA) functional class. 238

In real life, not all patients with a bioprosthesis require reoperation. $^{22} 3539$ Though sufficient data are not available in younger patients, limited life expectancy related to age precludes reoperation in the majority of cases. Life expectancy after aortic bioprosthesis implantation at age $60,65,70$, and 75 years are 15, 12, 10, and 7 years, respectively; the risks of SVD at these ages is $25 \%, 18 \%, 10 \%$, and $5 \%$, respectively. ${ }^{14}$ Thus, if 100 patients had bioprostheses initially, the number of patients who will need reoperation in these age groups will be $4,3,1$, and $<1$, respectively. ${ }^{22}$

Mechanical valves are also not free from reoperations. The annual risk of reoperation for mechanical valves ranges from $0.3 \%$ to $1.2 \% .^{12} 33{ }^{40}$ In contrast to bioprostheses, there is a constant hazard of reoperation with mechanical valves. If 
operated on between 40 and 60 years of age, the linearised reoperation rate ranges from $0.2 \%$ to $0.6 \%$ per patient-year. ${ }^{33}$ Similarly, in patients 61-70 years of age, the 15-year actuarial freedom from reoperation was $82.2 \%$ for mechanical valves. ${ }^{41}$ Most of the mechanical valves needed emergency reoperations for valve thrombosis and had a very high mortality rate of 20$24 \%$. $^{736}$

When considering the possibility of reoperation at the time of prosthesis selection, the future availability of valve-in-valve transcatheter aortic/mitral valve replacement for degenerated bioprosthesis should also be considered. Transcatheter valve insertion in degenerated bioprosthesis, both in the aortic and mitral positions, has shown promising results. There are technical and cost limitations at present. Patients who receive bioprosthetic valves now will likely develop SVD in the next 1015 years. With technological advances, and large numbers of implants, transcatheter valve implantation will become a safe and viable option.

\section{Valve thrombosis, thromboembolism, stroke, and other events}

Thrombosis of a mechanical valve may occur as a catastrophic event with the acute onset of heart failure, pulmonary oedema or cardiogenic shock. Acute valve thrombosis requires urgent thrombolytic therapy or emergency surgery, but mortality remains high. The incidence of obstructive valve thrombosis varies between $0.3 \%$ and $1.3 \%$ per patient-year and is higher in the mitral position. ${ }^{13} 42$

All prosthetic valves are susceptible to formation of thrombus that can subsequently embolise and can result in stroke or loss of function of other organs. The incidence ranges from $0.6 \%$ to $2.3 \%$ per patient-year. ${ }^{13}{ }^{23}$ Though several studies report similar incidences of thromboembolism among mechanical valves and bioprostheses, ${ }^{11} 12$ others have reported a higher risk of thromboembolism in patients with a mechanical valve, especially in the mitral position. 623244344

No differences in stroke rates were observed in patients with bioprosthetic valves compared with mechanical valves. ${ }^{17}$ The 15 -year cumulative incidence of stroke was 7.7\% (95\% CI 5.7\% to $9.7 \%)$ in the bioprosthesis group and $8.6 \%$ (95\% CI $6.2 \%$ to $11.0 \%$ ) in the mechanical prosthesis group (HR 1.04, 95\% CI 0.75 to 1.43$)$. Most large series have found the incidence of prosthetic valve endocarditis to be the same whether a mechanical or a bioprosthetic valve is used. ${ }^{45}$ However, mechanical valves appear to be at a higher risk than bioprosthetic valves of infection within the first 3 months after implantation. ${ }^{47}$ Overall, mechanical valves were associated with greater valve related morbidity. Up to a follow-up of 15 years, the incidence of composite valve related morbidity was much higher with mechanical valves (table 4 ).
Survival

Two large historical randomised clinical trials compared the outcomes after valve replacement with a first-generation porcine heterograft and the original Bjork-Shiley tilting-disc mechanical valve: the Edinburgh Heart Valve Trial ${ }^{11}$ conducted between 1975 and 1979 with an average follow-up of 12 years; and the Veteran Affairs (VA) Cooperative Study on Valvular Heart Disease, conducted between 1979 and 1982 with an average follow-up of 15 years. ${ }^{12}$ The Edinburgh study showed no difference in mortality at 20 years between mechanical valve and biological valve $(25.0 \%$ vs $22.6 \%, \mathrm{p}=0.39)$. In the VA study, there were similar outcomes at 5 and 11 years, but after 15 years follow-up all-cause mortality after AVR was lower with the mechanical valve $(66 \%$ vs $79 \%, \mathrm{p}=0.02)$ but not after MVR $(81 \%$ vs $79 \%, p=0.30)$. The VA trial had several other important findings: (1) the majority (60\%) of the deaths after AVR were not related to the prosthesis, but to the associated comorbid conditions; and (2) survival in the first 8 years after valve replacement was virtually identical for mechanical and porcine valves. Thus, in the patient with no comorbid conditions, survival at 10 years would be similar whether a mechanical or a bioprosthetic valve was used. ${ }^{2}$

These trials had several limitations. Both the trials studied first-generation porcine bioprostheses and the Bjork-Shiley mechanical valve, all of which are now obsolete. The patient populations were also heterogeneous without any focus on specific age group. By present standards, perioperative mortality was also extremely high (15.5\% in MVR). Thus, extrapolation of these data to modern practice should be done with caution. The most recent randomised clinical trial, using newer bioprostheses and mechanical valves in the aortic position, was performed between 1995 and 2003. ${ }^{48}$ At 13-year follow-up, there was no difference in overall mortality (biological vs mechanical: $27.5 \%$ vs $30.6 \%$ ), valve-related mortality $(6.7 \%$ vs $8.1 \%)$, and cardiac-related mortality $(16.7 \%$ vs $21.7 \%)$.

There are several retrospective studies which showed improved survival with mechanical valves. ${ }^{49-51}$ However, most of the larger series reported either no difference in early and late mortality or improved survival with bioprostheses. 1733445253 A recent systemic review and meta-analysis did not find any difference in risk factor-corrected overall death rate between mechanical or bioprosthetic aortic valves irrespective of age. ${ }^{54}$ Similarly, in a large retrospective study, Chan et $a^{33}$ compared mechanical and tissue AVR in 3062 patients with a combined follow-up of 22182 patient-years. They did not find any difference in valve related mortality in both the groups in patients $>40$ years of age (table 5). Ruel and colleagues ${ }^{40}$ reported no significant prosthesis- or age-related differences in late survival after bioprosthetic or mechanical valve implantation in patients $<60$ years of age.

Table 4 Linearised (\%/patient-year) rate of composite valve-related morbidity by age, and actuarial freedom from valve related morbidity at 15 years $^{33}$

\begin{tabular}{|c|c|c|c|c|c|c|}
\hline \multirow[b]{2}{*}{ Age (years) } & \multicolumn{3}{|c|}{ Valve related morbidity } & \multicolumn{3}{|c|}{ Actuarial freedom from valve related morbidity at 15 years } \\
\hline & Bioprosthesis (B) & Mechanical (M) & $\begin{array}{l}B \text { vs } M \\
p \text { values }\end{array}$ & Bioprosthesis (B) & Mechanical (M) & $\begin{array}{l}B \text { vs } M \\
p \text { values }\end{array}$ \\
\hline$\leq 40$ & 0.0 & 0.8 & 0.011 & & & \\
\hline $41-50$ & 0.0 & 1.3 & $<0.001$ & & & \\
\hline $51-60$ & 0.3 & 2.2 & $<0.001$ & $97.6 \% \pm 1.1 \%$ & $85.4 \% \pm 2.5 \%$ & $<0.001$ \\
\hline $61-70$ & 0.4 & 2.7 & $<0.001$ & $95.6 \% \pm 1.1$ & $81.5 \% \pm 3.7$ & $<0.001$ \\
\hline
\end{tabular}


Table 5 Incidence of valve related mortality, and actuarial freedom from valve related morbidity and mortality at 15 years $\mathrm{s}^{33}$

\begin{tabular}{|c|c|c|c|c|c|c|}
\hline \multirow[b]{2}{*}{ Age (years) } & \multicolumn{3}{|c|}{ Valve related mortality } & \multicolumn{3}{|c|}{ Actuarial freedom from valve related mortality at 15 years } \\
\hline & Bioprosthesis (B) & Mechanical (M) & $\begin{array}{l}B \text { vs } M \\
p \text { value }\end{array}$ & Bioprosthesis (B) & Mechanical (M) & $\begin{array}{l}B \text { vs } M \\
p \text { value }\end{array}$ \\
\hline$\leq 40$ & 1.1 & 0.0 & 0.003 & & & \\
\hline $41-50$ & 0.8 & 0.5 & 0.516 & & & \\
\hline $51-60$ & 0.6 & 0.5 & 0.646 & $91.8 \% \pm 2.4 \%$ & $94.1 \% \pm 2.6 \%$ & 0.76 \\
\hline $61-70$ & 1.0 & 1.1 & 0.738 & $82.8 \% \pm 2.7 \%$ & $89.3 \% \pm 3.3 \%$ & 0.37 \\
\hline
\end{tabular}

The major cause of mortality in bioprostheses is reoperation, whereas the major cause of death in patients with mechanical valves is anticoagulation related complications. Valve thrombosis and emergency surgery also contributes to mortality in mechanical valves. Van Geldorp et $a l^{14}$ showed that at 55 years of age, the risk of subsequent reoperation with a bioprosthesis is equal to that of bleeding with a mechanical valve. Similar findings were also reported by others. ${ }^{44} 55$ Although no significant difference has been found in overall survival after bioprosthesis or mechanical valve implantation, there is sufficient evidence to show that the use of a bioprosthesis is associated with better event-free survival. ${ }^{14}$ Similarly, use of a bioprosthesis is associated with less valve related morbidity (table 4). ${ }^{33}$

\section{Life expectancy}

A bioprostheses is opted for when the presumed durability of the bioprosthesis is more than the life expectancy of the patient. However, when deciding the life expectancy, traditionally and unintentionally, it is always considered equivalent to the average life expectancy in developed nations. Though the guidelines also mention country and patient-specific life expectancy, it is rarely followed in clinical practice; erroneously, it is assumed that all patients are going to survive up to the age of 7580 years. While deciding the patient's life expectancy, several factors should be taken into consideration.

\section{Relative survival}

The presence of valvular heart disease, even after valve replacement, affects survival adversely. Relative survival is a measure of

\begin{tabular}{ll}
$\begin{array}{l}\text { Table } 6 \text { Cardiac and non-cardiac factors which predict reduced } \\
\text { survival }^{62-64}\end{array}$ \\
\hline Serial number \\
\hline Cardiac factor \\
1 & \\
2 & Left ventricular dysfunction \\
3 & Severe pulmonary arterial hypertension \\
4 & Tricuspid valve involvement \\
5 & Atrial fibrillation \\
6 & Cardiomegaly \\
7 & Advanced functional class \\
8 & Coronary artery disease \\
9 & Left atrial enlargement \\
Non-cardiac factor & Left atrial thrombus \\
1 & \\
2 & Impaired renal function \\
3 & Diabetes \\
4 & Hypertension \\
5 & Smoking \\
\hline
\end{tabular}

the excess mortality among heart valve replacement patients compared with the general population. The relative survival rate is defined as the ratio of the observed survival in a group of patients during a specified time interval to the survival expected from the general population experience. ${ }^{56} 57$ Lindblom and colleagues have shown that relative survival in patients undergoing AVR and MVR was only $78 \%$ and $65 \%$, respectively. Relative survival is less in younger patients. ${ }^{58} 59$ The presence of higher NYHA functional class and/or AF further reduces the expected survival. At 10-year follow up, the presence of NYHA functional class III/IV and AF increases the mortality by $32 \%$ and $40 \%$, respectively. ${ }^{60}$ The presence of aortic regurgitation and mitral regurgitation also contribute to excess mortality. ${ }^{58} 60$ Simulated models have shown that the calculated life expectancy of a 60 -year-old patient receiving a bioprosthesis is 11.9 years. ${ }^{14}$ This is much shorter than the life expectancy of 22.6 years for 60 -year-olds reported by the US National Center for Health Statistics. $^{61}$

\section{Biological factors affecting survival}

Besides the chronological age of patients, several cardiac and non-cardiac factors decrease their life expectancy (table 6). Left ventricular dysfunction, tricuspid valve disease, pulmonary arterial hypertension, higher NYHA functional class, and AF represent advanced valvular heart disease and are associated with reduced survival. Thus, at a given point, age is not the only determinant of life expectancy. In developing countries, even young patients can present with a very advanced stage of valvular heart disease. The life expectancy of these patients is much lower than the national average.

\section{Socioeconomic factors affecting survival}

While considering the patient's life expectancy, it is important to consider the country/region/gender-specific life expectancy. The average life expectancy of a person in India is much less than that of someone in the USA. In 2004, the average predicted life expectancy at birth of an Indian and a US citizen were 62.2 years and 78 years, respectively. Also, in India the average life expectancy varies greatly among different states (table 7). Kerala, with better health infrastructure and higher

Table 7 Life expectancy at birth in 2004 in different Indian states $^{65}$

\begin{tabular}{ll}
\hline State & Life expectancy at birth (years) \\
\hline Kerala & 74.0 \\
Punjab & 69.2 \\
Gujrat & 64.2 \\
Bihar & 61.2 \\
Jharkhad & 58.0 \\
\hline
\end{tabular}


Table 8 Life expectancy at birth (years) in 2004 by gender and location in India ${ }^{66}$

\begin{tabular}{llll}
\hline & \multicolumn{2}{l}{ Gender } & \\
\cline { 2 - 4 } Location & Male & Female & Person \\
\hline Urban & 66.0 & 69.0 & 67.6 \\
Rural & 60.1 & 61.6 & 60.9 \\
Combined & 61.3 & 63.0 & 62.2 \\
\hline
\end{tabular}

literacy rates, has an average life expectancy of 74 years, whereas it is only 58 years in Madhya Pradesh, Jharkhand, and Chhatisgarh. Similarly, life expectancy is also affected by the patient's gender and location (urban vs rural) (table 8). Life expectancy of a rural male (60.2 years) is much less than that of urban female (69.0 years).

Life expectancy is a direct reflection of an individual's socioeconomic and educational status. ${ }^{67} 68$ Those from high-income households with good housing conditions, materially privileged households and small households, have a longer life expectancy compared to deprived persons. Also, those who have studied in college live longer than illiterate individuals.

\section{SUMMARY OF FINDINGS}

Mechanical valves have the advantage of durability but are accompanied by the risk of thromboembolism, problems of long-term anticoagulation, and associated risk of bleeding. In contrast, bioprosthetic valves do not require long-term anticoagulation, but carry the risk of structural valve degeneration and reoperation. Beyond the age of 40 years, the risk of reoperation with a bioprosthetic valve is equal to that of bleeding with a mechanical valve. Hence, there is no survival difference in patients older than 40 years who receive either a bioprosthetic or a mechanical valve.

SVD is a function of the patient's age. In the middle aged population, SVD starts at about 5 years in the mitral position and at 8 years in the aortic position, and patients will usually require the first elective reoperation after 10-12 years. Newer bioprostheses have a slower rate of SVD. The mortality of reoperation with a bioprosthesis has diminished to $5-7 \%$. In the case of mechanical valves, bleeding episodes are associated with very high mortality. In addition, there is a low but constant risk of emergency reoperation. Mortality from reoperation in patients with mechanical valves is much higher. Mechanical valves are also associated with higher valve related morbidity and problems of anticoagulation.

The calculation of life expectancy, based solely upon chronological age, is erroneous. In developing countries, the calculated life expectancy is much lower than that of Western populations. Hence, age-related Western cut-offs are not valid in developing countries. Besides age, the cardiac condition of the patient, systemic illnesses, socioeconomic status, gender, and geographical location also dictate the life expectancy of the patient. In developing countries, patients from rural backgrounds and low socioeconomic status very often present with advanced disease. Despite being young in age, the life expectancy of these patients is limited. Thus, when selecting the prosthesis, life expectancy should be calculated using all the relevant factors, rather than age alone.

\section{CHOICE OF PROSTHESES}

As discussed above, the choice of prosthetic heart valve should be a shared decision-making process that accounts for the patient"s values and preferences, with full disclosure of the indications for and risks of anticoagulant therapy and the potential need for and risk of reoperation. ${ }^{3}$ The main determinants of valve selection are the individual patient's life expectancy, the patient's tolerance for repeat valve replacement, and the use of oral anticoagulants with its associated changes in lifestyle.

For the purpose of prosthesis selection, patients can be grouped on the basis of life expectancy. Patients with long life expectancy (more than 20-25 years), depending upon chronological age, will require more than one reoperation if a bioprosthesis is implanted. Patients with limited life expectancy $(<10-15$ years) will not require reoperation if a bioprosthesis is used. Patients with a moderate life expectancy (10-20 years) will require one reoperation if a bioprosthesis is implanted at the initial operation. A mechanical valve is reasonable in a willing patient with long life expectancy when there is no contraindication to oral anticoagulants and reliable, quality anticoagulation can be ensured. However, if anticoagulation is either not desired because of lifestyle/profession, or not feasible (compliance problems, availability or monitoring issues), a bioprosthesis is the valve of choice. In patients with limited life expectancy, a bioprosthesis may be considered safely. In patients with moderate life expectancy, because there is no significant survival benefit associated with one prosthesis type over another, decision making is focused on lifestyle considerations, including the burden of anticoagulation medication and monitoring, and the relative risks of major morbidity-primarily stroke, reoperation, and major bleeding events. ${ }^{17}$ Thus, a careful evaluation is required, judging the risk of one reoperation with a bioprosthesis vis-à-vis risk and the problems of life-long anticoagulation. Availability, monitoring, cost, lifestyle, profession, and socioeconomic background should be carefully considered before planning life-long anticoagulation. Table 9 lists the factors that make anticoagulation difficult.

\section{The index case}

A 44-year-old manual labourer from a village in India presented with progressive dyspnoea on exertion of 2 years duration. Two months before presentation, he had stopped going to work because of his dyspnoea. He was diagnosed as having a calcific mitral valve with severe stenosis (mitral valve area $0.8 \mathrm{~cm}^{2}$ ) and mild regurgitation. He had moderate pulmonary artery hypertension. His aortic and tricuspid valves were normal. He had no coronary artery disease and was in sinus rhythm. He was referred for valve replacement surgery.

\begin{tabular}{ll}
$\begin{array}{l}\text { Table } 9 \\
\text { difficult }\end{array}$ & Factors which make reliable, quality anticoagulation \\
\hline Serial number & Factors \\
\hline 1 & Rural background \\
2 & Underdeveloped region \\
3 & Inadequate medical services \\
4 & Non-availability of anticoagulants \\
5 & Manual labourer \\
6 & Female gender \\
7 & Non-earning status in family \\
8 & Poor socioeconomic status \\
9 & Lack of education \\
10 & Mental illness \\
\hline
\end{tabular}


Should this patient receive a mechanical valve or a bioprosthesis? When choosing a prosthetic valve for this patient, several issues need to be taken into consideration. Important considerations are: life expectancy of the patient; occupation of the patient; availability, cost, and monitoring of anticoagulation; monitoring of valve function and other valve related complications; and the possibility of reoperation. The predicted life expectancy of a manual labourer from rural India at this age would range from 20 to 25 years. The relative survival of patients with MVR ranges from $70 \%$ to $80 \%$. As this patient does not have any other risk factor predicting reduced survival, the life expectancy of this patient could be assumed to be 14 to 20 years. Being a manual labourer, this patient is prone to repeated injuries and thus is at an increased risk of life-threatening haemorrhage due to the use of anticoagulants that are mandatory with a mechanical valve. As the patient is a resident of a village, he is unlikely to have access to a health facility where his anticoagulation status can be reliably monitored. A mechanical valve also requires frequent assessment with cinefluoroscopy/echocardiography. In a rural setting these facilities are unlikely to be available. In addition to the costs, the patient will be required to travel frequently to a town/city for these investigations. This will keep him away from work that will adversely impact his already compromised economic status and burden him further. As medical practitioners in rural India frequently may not fully understand the consequences of using oral anticoagulants, management of other concurrent illnesses will also become difficult. In contrast, a bioprosthesis eliminates the risks of sudden prosthetic valve dysfunction and death, reduces the risk of anticoagulation related haemorrhage, avoids repeated visits to the hospital, reduces the costs of treatment, and is associated with an acceptable quality of life. The currently available bioprostheses are expected to last for 10-12 years in this patient. He can safely undergo a reoperation once valve deterioration occurs later in life. Developments in tissue valves and transcatheter valve technology are expected to eliminate the need for a second reoperation. Thus, a tissue valve appears to best serve the needs of this patient.

Key messages

Calculation of life expectancy, based solely upon chronological age, is erroneous. Age related Western cut-offs are not valid in developing countries. Besides age, cardiac condition of the patient, systemic illnesses, socio-economic status, gender and geographical location also decide the life expectancy of the patients.

- Selection of the prosthetic valve substitute should be based on: aspiration of the patient, life expectancy, socio-economic and educational background, occupation of the patient, availability, cost, monitoring of anti-coagulation, monitoring of valve function and other valve related complications, and possibility of re-operation.

Contributors SKC: primary author, planning and writing the manuscript. ST: revising the work critically for important intellectual content, and final approval of the version submitted. BA: revising the work critically for important intellectual content, and final approval of the version submitted.

Competing interests None declared.
Provenance and peer review Commissioned; externally peer reviewed.

\section{REFERENCES}

1 Harken DE. Heart valves: ten commandments and still counting. Ann Thorac Surg 1989;48(Suppl. 3):S18-19.

2 Huang G, Rahimtoola SH. Prosthetic heart valve. Circulation 2011;123:2602-5.

3 Nishimura RA, Otto CM, Bonow RO, et al. 2014 AHA/ACC guideline for the management of patients with valvular heart disease: executive summary: a report of the American College of Cardiology/American Heart Association Task Force on Practice Guidelines. Circulation 2014;129:2440-92.

4 Burdon TA, Miller DC, Oyer PE, et al. Durability of porcine valves fifteen years in a representative North American patient population. J Thorac Cardiovasc Surg 1992;103:238-51.

5 Hoffmann G, Lutter G, Cremer J. Durability of bioprosthetic cardiac valves. Dtsch Arztebl Int 2008;105:143-8.

6 Vahanian A, Alfieri O, Andreotti F, et al., Joint Task Force on the Management of Valvular Heart Disease of the European Society of Cardiology (ESC); European Association for Cardio-Thoracic Surgery (EACTS). Guidelines on the management of valvular heart disease (version 2012). Eur Heart J 2012;33:2451-96.

7 EL Oakley R, Kliene P, Bach DS. Choice of prosthetic heart valve in today's practice. Circulation 2008;117:253-6.

8 Rahimtoola SH. Choice of prosthetic heart valve for adult patients. J Am Coll Cardiol 2003;41:893-904

9 Bach DS. Choice of prosthetic heart valves: update for the next generation. J Am Coll Cardiol 2003:42:1717-19.

10 [No authors listed]. Adjusted-dose warfarin versus low-intensity, fixed-dose warfarin plus aspirin for high-risk patients with atrial fibrillation: stroke prevention in atrial fibrillation III randomized clinical trial. Lancet 1996:348:633-8.

11 Oxenham H, Bloomfield P, Wheatley DJ, et al. Twenty year comparison of a Bjork-Shiley mechanical heart valve with porcine bioprostheses. Heart 2003;89:715-21.

12 Hammermeister K, Sethi GK, Henderson WG, et al. Outcomes 15 years after valve replacement with a mechanical versus a bioprosthetic valve: final report of the Veterans Affairs randomized trial. J Am Coll Cardiol 2000;36:1152-8.

13 Vesey JM, Otto CM. Complications of prosthetic heart valves. Curr Cardiol Rep 2004;6:106-11.

14 van Geldorp MW, Eric Jamieson WR, Kappetein AP, et al. Patient outcome after aortic valve replacement with a mechanical or biological prosthesis: weighing lifetime anticoagulant related event risk against reoperation risk. J Thorac Cardiovasc Surg 2009;137:881-6.

15 Aupart M, Diemont F, Babuty D, et al. Results intermediares avec la prosteses valvulaire a ailettes carbomedics. Arch Mal Coeur Vaiss 1997;90:457-62

16 Florath I, Albert A, Rosendahl U, et al. Mid-term outcome and quality of life after aortic valve replacement in elderly people: mechanical versus stentless biological valves. Heart 2005;91:1023-9.

17 Chiang YP, Chikwe J, Moskowitz AJ, et al. Survival and long-term outcomes following bioprosthetic vs mechanical aortic valve replacement in patients aged 50 to 69 years. JAMA 2014;312:1323-9.

18 Petersen P, Grind M, Alder J, SPORTIF II Investigators. Ximelagatran versus warfarin for stroke prevention in patients with nonvalvular atrial fibrillation. SPORTIF II: a dose-guiding, tolerability, and safety study. J Am Coll Cardiol 2003;41:1445-51.

19 Kimmell SE, Chen Z, Price M, et al. The influence of patient adherence on anticoagulation control with warfarin: results from the International Normalized Ratio Adherence and Genetics (IN-RANGE) Study. Arch Intern Med 2007; 167:229-35.

20 Al Halees Z. The choice of valve prosthesis: are the guidelines for everyone? Asian Cardiovasc Thorac Ann 2007;15:457-8.

21 Dürrleman N, Pellerin M, Bouchard D, et al. Prosthetic valve replacement: twenty-year experience at the Montreal Heart Institute. J Thorac Cardiovasc Surg 2004; 127:1388-92.

22 Rahimtoola SH. Choice of prosthetic heart valve in adults an update. J Am Coll Cardiol 2010;55:2413-26.

23 Bonow RO, Carabello BA, Kanu C, et al. ACC/AHA 2006 guidelines for the management of patients with valvular heart disease: a report of the American College of Cardiology/American Heart Association Task Force on Practice Guidelines (writing committee to revise the 1998 guidelines for the management of patients with valvular heart disease): developed in collaboration with the Society of Cardiovascular Anesthesiologists: endorsed by the Society for Cardiovascular Angiography and Interventions and the Society of Thoracic Surgeons. Circulation 2006;114:e84-231.

24 Jamieson WR, Cartier PC, Allard M, et al. Surgical management of valvular heart disease 2004. Can J Cardiol 2004;20(Suppl E):7E-120E.

25 Schoen FJ, Levy RJ. Calcification of tissue heart valve substitutes: progress toward understanding and prevention. Ann Thorac Surg 2005;79:1072-80. 
26 Ruel M, Kulik A, Rubens FD, et al. Late incidence and determinants of reoperation in patients with prosthetic heart valves. Eur J Cardiothorac Surg 2004;25:364-70.

27 Jamieson WR, Ling $H$, Burr LH, et al. Carpentier-Edwards supraannular bioprosthesis evaluation over 15 years. Ann Thorac Surg 1998;66(6 Suppl):S49-52.

28 David TE, Ivanov J, Armstrong $S$, et al. Late results of heart valve replacement with the Hancock II bioprosthesis. J Thorac Cardiovasc Surg 2001;121:268-78.

29 Cohn LH, Collins JJ Jr, Rizzo RJ, et al. Twenty-year follow-up of the Hancock modified orifice porcine aortic valve. Ann Thorac Surg 1998;66 (Suppl):S30-4.

30 Banbury MK, Cosgrove DM III, White JA, et al. Age and valve size effect on the long-term durability of the Carpentier-Edwards aortic pericardial bioprosthesis. Ann Thorac Surg 2001;72:753-7.

31 Jamieson WRE, Marchand A, Pelletier $\mathrm{CL}$, et al. Structural valve deterioration in mitral replacement surgery. Comparison of Carpentier-Edwards supra-annular porcine and Perimount pericardial. J Thorac Cardiovasc Surg 1999;118:297-305.

32 Bach DS, Metras J, Doty JR, et al. Freedom from structural valve deterioration among patients 60 years of age and younger undergoing Freestyle aortic valve replacement. J Heart Valve Dis 2007;16:649-55.

33 Chan V, Jamieson WR, Germann E, et al. Performance of bioprostheses and mechanical prostheses assessed by composites of valve-related complications to 15 years after aortic valve replacement. J Thorac Cardiovasc Surg 2006;131:1267-73.

34 Chan V, Lam BK, Rubens FD, et al. Long-term evaluation of biological versus mechanical prosthesis use at reoperative aortic valve replacement. J Thorac Cardiovasc Surg 2012;144:146-51.

35 Chan V, Malas T, Lapierre $H$, et al. Reoperation of left heart valve bioprostheses according to age at implantation. Circulation 2011;124(11 Suppl):S75-80.

36 Roques F, Michel P, Gladstone AR, et al. The logistic EuroSCORE. Eur Heart J 2003;24:1-2.

37 Potter DD, Sundt TM III, Zehr KJ, et al. Operative risk of reoperative aortic valve replacement. J Thorac Cardiovasc Surg 2005;129:94-103.

38 Jamieson WRE, Burr LH, Miyagishima RT, et al. Re-operation for bioprosthetic aortic structural failure-risk assessment. Eur J Cardiothorac Surg 2003;24:873-8.

39 Kaneko T, Cohn LH, Aranki SF. Tissue valve is the preferred option for patients aged 60 and older. Circulation 2013;128:1365-71.

40 Ruel $M$, Chan V, Bédard $P$, et al. Very long-term survival implications of heart valve replacement with tissue versus mechanical prostheses in adults $<60$ years of age. Circulation 2007;116(11 Suppl):I294-300.

41 Prasongsukarn K, Jamieson WR, Lichtenstein SV. Performance of bioprostheses and mechanical prostheses in age group 61-70 years. J Heart Valve Dis 2005;14:501-11.

42 Roudaut R, Serri K, Lafitte $S$. Thrombosis of prosthetic heart valves: diagnosis and therapeutic considerations. Heart 2007;93:137-42.

43 Pibarot P, Demesnil JG. Prosthetic heart valves: selection of the optimal prosthesis and long-term management. Circulation 2009;119:1034-48.

44 Kulik A, Bédard P, Lam BK, et al. Mechanical versus bioprosthetic valve replacement in middle-aged patients. Eur J Cardiothorac Surg 2006;30:485-91.

45 Grover FL, Cohen DJ, Oprian C, et al. Determinants of the occurrence of and survival from prosthetic valve endocarditis: experience of the Veterans Affairs Cooperative Study on Valvular Heart Disease. J Thorac Cardiovasc Surg 1994;108:207-14.

46 Sabik JF, Lytle BW, Blackstone EH, et al. Aortic root replacement with cryopreserved allograft for prosthetic valve endocarditis. Ann Thorac Surg 2002;74:650-9.
47 Habib G, Thuny F, Avierinos JF. Prosthetic valve endocarditis: current approach and therapeutic options. Prog Cardiovasc Dis 2008;50:274-81.

48 Stassano P, Di Tommaso L, Monaco M, et al. Aortic valve replacement: a prospective randomized evaluation of mechanical versus biological valves in patients aged 55 to 70 years. J Am Coll Cardiol 2009;54:1862-8.

49 Hanania G, Michel PL, Montely JM, et al. Outcomes 15 years after valve replacement with a mechanical versus a bioprosthetic valve in patients between 60 and 70 years of age. J Am Coll Cardiol 2002;39:S423A.

50 Brown ML, Schaff HV, Lahr BD, et al. Aortic valve replacement in patients aged 50 to 70 years: improved outcome with mechanical versus biologic prostheses. J Thorac Cardiovasc Surg 2008;135:878-84; discussion 884.

51 Suri RM, Schaff HV. Selection of aortic valve prostheses: contemporary reappraisal of mechanical versus biologic valve substitutes. Circulation 2013;128:1372-80.

52 Schelbert EB, Vaughan-Sarrazin MS, Welke KF, et al. Valve type and long-term outcomes after aortic valve replacement in older patients. Heart 2008;94: 1181-8.

53 Peterseim D, Can YY, Cheruvu S, et al. Long-term outcome after biological versus mechanical aortic valve replacement in 841 patients. J Thorac Cardiovasc Surg 1999;117:890-7.

54 Lund 0 , Bland M. Risk-corrected impact of mechanical versus bioprosthetic valves on long-term mortality after aortic valve replacement. J Thorac Cardiovasc Surg 2006;132:20-6.

55 Birkmeyer NJ, Birkmeyer JD, Tosteson ANA, et al. Prosthetic valve type for patients undergoing aortic valve replacement: a decision analysis. Ann Thorac Surg 2000;70:1946-52.

56 Ederer F, Axtell LM, Cutler SJ. The relative survival rate: a statistical methodology. Natl Cancer Inst Monogr 1961;6:101-21.

57 Cutler SJ, Axtell LM, Schottenfeld D. Adjustment of long-term survival rates for deaths due to intercurrent disease. J Chron Dis 1969;22:485-91.

58 Lindblom $D$, Lindblom $U$, Qvist J, et al. Long-term relative survival rates after heart valve replacement. J Am Coll Cardiol 1990;15:566-73.

59 Puvimanasinghe JP, Takkenberg JJ, Eijkemans MJ, et al. Prognosis after aortic valve replacement with the Carpentier-Edwards pericardial valve: use of microsimulation. Ann Thorac Surg 2005;80:825-31.

60 Kvidal P, Bergström R, Hörte LG, et al. Observed and relative survival after aortic valve replacement. J Am Coll Cardiol 2000;35:747-56.

61 U.S. National Center for Health Statistics. National Vital Statistics Reports, Deaths: Preliminary Data for 2008;59.

62 Garcia A, Cartier R, Panisi P, et al. Factors influencing early and late survival in patients with combined mitral valve replacement and myocardial revascularization and in those with isolated replacement. Ann Thorac Surg 1987;44:607-13.

63 Rahimtoola SH. Lessons learned about the determinants of the results of valve surgery. Circulation 1988;78:1503-7.

64 Turina J, Stark T, Seifert B, et al. Predictors of the long-term outcome after combined aortic and mitral valve surgery. Circulation 1999;100(19 Suppl):I148-53.

65 Life Expectancy at Birth by Gender, 1992-2004 Table 5A.10, India Human Development Index Report, page 287.

66 Compendium of India's Fertility and Mortality Indicators, based on SRS, Registrar General of India.

67 OECD Health Data 2012; The World Bank World Development Indicators Online.

68 Sauvaget C, Ramadas K, Fayette J, et al. Socio-economic factors \& longevity in a cohort of Kerala State, India. Indian J Med Res 2011;133:479-86. 